\title{
AVALIAÇÃO DA QUALIDADE MICROBIOLÓGICA DO QUEIJO TIPO MINAS PADRÃO COMERCIALIZADO NA CIDADE DE SÃO LUIS, MA
}

\author{
A.C.M. de Melo, L.M.C. Alves, F.N. Costa \\ Universidade Estadual do Maranhão, Centro de Ciências Agrárias, Departamento de Patologia, Cidade \\ Universitária Paulo VI, s/no, CEP 65055-970, São Luis, MA, Brasil. E-mail: franeidec@yahoo.com.br
}

\section{RESUMO}

\begin{abstract}
No período de outubro de 2006 a maio de 2007, foi avaliada a qualidade microbiológica de 30 amostras de queijo tipo Minas Padrão comercializados em diferentes supermercados do Município de São Luis, MA, por meio da contagem de bactérias aeróbias mesófilas, psicrotróficas, Staphylococcus coagulase positiva e pesquisa de Salmonella spp. As contagens médias de bactérias aeróbias

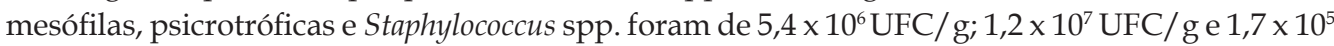
$\mathrm{UFC} / \mathrm{g}$, respectivamente. Para os valores obtidos na contagem de Staphylococcus coagulase positiva, 6,6\% das amostras apresentaram-se em desacordo com o estabelecido pela Anvisa. Com relação à pesquisa de Salmonella spp., não foi evidenciada a presença deste micro-organismo em $25 \mathrm{~g}$ do produto, estando ele dentro dos padrões estabelecidos para esse agente. Estes resultados indicam que o queijo analisado nesta pesquisa apresentava uma qualidade microbiológica insatisfatória podendo o produto ser um importante veículo de intoxicação alimentar estafilocócica.
\end{abstract}

PALAVRAS-CHAVE: Queijo minas padrão, mesófilos, psicrotróficos, Staphylococcus coagulase positiva.

\begin{abstract}
MICROBIOLOGICAL EVALUATION OF QUALITY OF MINASPADRÃOCHEESEMARKETED IN THE CITY OF SÃO LUIS, MA, BRAZIL. From October 2006 to May 2007, the microbiological quality of 30 samples of cheese of the type Minas Padrão sold in different supermarkets of the city of São Luis, MA, Brazil, was evaluated by the count of aerobic mesophilic bacteria, psychrotrophic bacteria, Staphylococcus coagulase positive bacteria, and examination for Salmonella spp. The average counts of aerobic mesophilic bacteria, psychrotrophic and Staphylococcus spp. were $5.4 \mathrm{x}$ $10^{6} \mathrm{CFU} / \mathrm{g}, 1.2 \times 10^{7} \mathrm{CFU} / \mathrm{g}$ and $1.7 \times 10^{5} \mathrm{CFU} / \mathrm{g}$, respectively. In regard to the values obtained from the count of Staphylococcus coagulase positive bacteria, $6.6 \%$ of the samples submitted were out of conformance with the standard set by Anvisa. Regarding the examination for Salmonella spp., the presence of this microorganism was not detected in $25 \mathrm{~g}$ of the product, so the cheese was in conformance with the standards established for this organism. These results indicate that the cheese examined in this study had an unsatisfactory microbiological quality, meaning that the product could be an important vehicle for staphylococcal food poisoning.
\end{abstract}

KEY WORDS: Minas Padrão cheese, mesophilic, psychrotrophic, coagulase-positive Staphylococcus.

\section{INTRODUÇÃO}

O queijo destaca-se entre os derivados lácteos pelo alto teor de proteína e outros nutrientes. Com o desenvolvimento tecnológico de sua produção surgiram, no Brasil, muitas variedades, sendo algumas de expressão regional. Esta atividade, de importância econômica e social, é exercida por inúmeros pequenos produtores estabelecidos, principalmente na zona rural. Há uma variedade de queijos que são elaborados de forma artesanal e geralmente a partir de leite cru, sem os devidos cuidados de higiene ou em indústrias que não adotam Boas Práticas de Fabricação (Borges et al., 2003).

O queijo Minas Padrão é o produto obtido de leite integral ou padronizado, pasteurizado, de massa crua, prensado mecanicamente e devidamente maturado durante 20 dias. Deve apresentar formato cilíndrico, de faces planas e bordos retos, formando ângulo vivo; peso entre $1 \mathrm{~kg}$ a $1.200 \mathrm{~kg}$, crosta fina; 
consistência semidura, macia, de untura manteigosa; textura, buracos mecânicos e em cabeça de alfinete, pouco numerosos; cor branco-creme, homogênea; odor e sabor próprios, ácidos, agradáveis e não picantes segundo Riispoa (BRASIL, 1997).

Este importante derivado do leite é apreciado tanto pelo seu valor nutritivo como pelo seu sabor que atende aos mais exigentes paladares. No entanto, as condições de processamento, armazenamento e comercialização podem comprometer suas características organolépticas, bem como torná-lo impróprio para o consumo, em virtude da contaminação por micro-organismos responsáveis por doenças veiculadas por alimentos (RAIMUNDO, 1992, apud Araujo et al., 2001).

A avaliação da qualidade dos derivados do leite é realizada não somente para verificar as condições higiênico-sanitárias, mas também para estimar a vida útil do produto (Sousa, 2005).

De acordo com SiLva Junior (1992), temperatura inadequada durante o preparo e conservação dos alimentos, contaminação cruzada, equipamentos e utensílios higienizados inadequadamente e manipulação por pessoas infectadas (assintomático ou não) são os fatores mais incriminados no processo de contaminação alimentar, principalmente queijos, cuja contaminação microbiana assume destacada relevância em saúde pública (PERESI et al., 2001).

Em termos gerais, dentro do campo da microbiologia de alimentos, sem dúvida as contaminações microbianas dos alimentos são indesejáveis e inclusive nocivas. Este aspecto é encarado com tal rigor que, para se conhecer a existência de possíveis deficiências higiênicas, as quais implicariam em contaminações alimentares, voltam-se as atenções para grupos de micro-organismos, desde aqueles considerados indicadores, como também para os patogênicos que encontram no alimento um meio propício para o desenvolvimento e até mesmo a liberação de substâncias tóxicas (Franco; AlmeIDA, 1992).

Dentre alguns micro-organismos importantes em alimentos destacamos: a Salmonella spp., causadora de intoxicação alimentar e o Staphylococcus aureus, que é toxigênico e produtor de toxina termoestável pré-formada no alimento (SALOTTI et al., 2006),

O consumo de queijos e outros alimentos contaminados por micro-organismos patogênicos representa, portanto, um risco à saúde pública, tendo notável importância e destaque a análise microbiológica de alimentos, cuja finalidade é avaliar as condições higiênico-sanitárias e os aspectos microbiológicos desses produtos (AlmeIda; Franco, 2003).

Devido a grande ocorrência de intoxicações de origem alimentar, e sendo o queijo um dos derivados lácteos produzidos, na maioria das vezes, de forma artesanal, sem os devidos cuidados higiênico-sanitários e a existência de poucos estudos com o queijo tipo Minas Padrão, é que se realizou esta pesquisa com o objetivo de avaliar a qualidade microbiológica deste produto comercializado em supermercados do Município de São Luis, MA, quantificando bactérias aeróbias mesófilas, psicrotróficas, Staphylococcus spp. e pesquisando Staphylococcus coagulase positiva e Salmonella spp.

\section{MATERIAL E MÉTODOS}

Foram analisadas 30 amostras de queijos tipo Minas Padrão procedentes de diferentes supermercados do Município de São Luis, MA, no período de outubro de 2006 a maio de 2007. As amostras inspecionadas eram vendidas sob refrigeração embaladas a vácuo e contendo as devidas informações nas embalagens. Todas as amostras adquiridas encontravam-se dentro do prazo de validade estipulado nas embalagens. As amostras foram acondicionadas em caixa isotérmica e transportadas para o laboratório de Microbiologia de Alimentos e Água da Universidade Estadual do Maranhão, onde foram feitas as análises.

\section{Pesagem e diluição das amostras}

De cada amostra de queijo foram pesadas, assep-ticamente, $25 \mathrm{~g}$ do produto que foi homogenizado em $225 \mathrm{~mL}$ de água peptonada tamponada a $0,1 \%$, a fim de obter-se a diluição $\left(10^{-1}\right)$. A partir desta diluição, foram realizadas, em tubos de ensaio contendo 9 $\mathrm{mL}$ de água peptonada tamponada a $0,1 \%$, diluições decimais sucessivas até $10^{-5}$.

Contagem de bactérias aeróbias mesófilas e psicrotróficas (BRASIL, 2003)

Foram tomadas, a partir das diluições decimais, alíquotas de 1,0 mL e semeadas em ágar padrão (PCA) para contagem. As amostras foram homogeneizadas, incubadas a $35^{\circ} \mathrm{C}$ por 24 a 48 horas para mesófilos, e à temperatura de 22 a $25^{\circ} \mathrm{C}$, em estufa B.O.D., por um período de 5 dias, no caso dos psicrotróficos.

Contagem de Staphylococcus spp. e pesquisa de Staphylococcus coagulase positiva (BRASIL, 2003)

Utilizou-se o meio ágar Baird Parker, depositando-se $0,1 \mathrm{~mL}$ de cada diluição, sobre a superfície do ágar. Com o auxílio de uma alça de Drigalsky, semeou-se o inóculo por toda a superfície do meio e as placas foram incubadas a $35-37^{\circ} \mathrm{C}$, por 24 a 48 horas. Após o período de incubação, foram selecionadas as placas contendo entre 25 a 250 colônias típicas: negras, lisas, pequenas circundadas por zona opaca e/ou halo transparente. Em seguida, 3 a 5 colônias típicas de cada 
placa foram inoculadas em tubos, contendo $1 \mathrm{~mL}$ de caldo infusão cérebro coração (BHI), incubando-se a $35-37^{\circ} \mathrm{C}$, por 24 horas. A partir do cultivo crescido em BHI, realizou-se a prova de coagulase, conforme metodologia de Vanderzant; Aplitts-Toesser (1992).

\section{Pesquisa de Salmonella spp. (ICMF, 1978).}

Vinte cinco gramas de cada amostra foram transferidos para frascos contendo $225 \mathrm{~mL}$ de caldo de pré-enriquecimento. Em seguida, as amostras foram incubadas em estufa a $35^{\circ} \mathrm{C}$, por 24 horas. Após a incubação, foram transferidas de cada amostra alíquotas de $1 \mathrm{~mL}$ do caldo pré-enriquecedor para 2 tubos de ensaio, um contendo caldo de selenito-cistina e outro contendo caldo Rappaport Vassiliadis, incubados a $35^{\circ} \mathrm{C}$ por 24 horas. Do crescimento nos meios de enriquecimento seletivo foram transferidos, com o auxilio de uma alça de semeadura, alíquotas do inóculo para placas contendo os meios, agar verde brilhante vermelho-de-fenol-lactose-sacarose e agar Salmonela - Shigella (SS) e incubadas a $37^{\circ} \mathrm{C}$ por 24 horas.

\section{RESULTADOS E DISCUSSÃO}

$\mathrm{Na}$ Tabela 1 estão apresentados os valores mínimo, médio e máximo para bactérias aeróbias mesófilas, psicrotróficas e Staphylococcus spp. encontrados nas 30 amostras de queijo tipo Minas Padrão comercializados no Município de São Luis, MA. Pelos dados encontrados, observou-se que o produto analisado apresentou uma elevada população de bactérias aeróbias mesófilas $\left(1 \times 10^{8} \mathrm{UFC} / \mathrm{g}\right)$ e psicrotróficas $\left(1,2 \times 10^{8} \mathrm{UFC} / \mathrm{g}\right)$ (Tabela 1). Segundo ReIs et al. (2006), a contagem de bactérias aeróbias me-sófilas é geralmente adotada para avaliar principalmente as condições higiênico-sanitárias da indústria. Com isso podemos suspeitar que o ambiente no qual foi produzido o queijo Minas Padrão, analisado nesta pesquisa, apresentava condições higiênico-sanitárias insatisfatórias devido a alta contaminação do produto por estas bactérias.
SCHEID FILHo et al. (2004), ao avaliarem a qualidade microbiológica do queijo colonial produzido no Município de Três Passos, região Noroeste do Rio Grande do Sul, observaram uma alta contagem de bactérias mesófilas aeróbias $\left(1,4 \times 10^{9} \mathrm{UFC} / \mathrm{g}\right)$ nas amostras o que, segundo os autores, pode ser decorrente de condições precárias de higiene na produção, processamento e/ou manipulação do produto, assim como da falta de pasteurização e controle de qualidade da matéria-prima. Ainda segundo os mesmos autores, foram encontradas altas contagens de bactérias psicrotróficas $\left(2,2 \times 10^{7} \mathrm{UFC} / \mathrm{g}\right)$ em algumas amostras, o que provavelmente seja consequência de um longo período de refrigeração no qual os queijos permaneceram antes de serem oferecidos para consumo.

De acordo com a Tabela 2, duas $(6,6 \%)$ das amostras de queijo analisadas apresentaram valores $(\geq$ $8,5 \times 10^{6} \mathrm{UFC} / \mathrm{g}$ ) acima do padrão estabelecido pela Agência Nacional de Vigilância Sanitária - BRASIL (2001), resolução $\operatorname{RDC}^{\circ} 12$ (de 2 de janeiro de 2001), que estabelece o valor de $\leq 5,0 \times 10^{2} \mathrm{UFC} / \mathrm{g}$ para cepas de estafilococos produtoras de coagulase em queijos frescos ou maturados colhidos no comércio. Estes achados nos levam a sugerir que hajam algumas falhas no processamento do produto, como a má manipulação do alimento, utilização incorreta da temperatura de conservação e condições higiênico sanitárias insatisfatórias. Para enfatizar este achado, ressalta-se a pesquisa realizada por PereIRA (2006) que ao analisar queijo coalho comercializado em supermercados na Cidade de São Luis, MA, encontrou contagens de $10^{5}$ a $10^{7} \mathrm{UFC} / \mathrm{g}$ para Staphylococcus spp. e duas amostras contaminadas por Staphylococcus coagulase positiva, sugerindo falhas no processo de embalagem, transporte e armazenamento desse produto na indústria.

ARRUDA et al. (2007), ao pesquisarem a ocorrência de Staphylococcus coagulase positiva em queijos Minas tipos frescal e padrão comercializados nas feiras-livres de Goiânia, GO, observaram que, para o queijo Minas padrão, os valores médios encontrados foram de $1,8 \times 10^{5} ; 1,3 \times 10^{3} ; 1,3 \times 10^{4}$, e que essas elevadas contagens de Staphylococcus coagulase positivo podem representar perigo para o consumidor.

Tabela 1 - Contagens de bactérias aeróbias mesófilas, psicrotróficas e Staphylococcus spp. em 30 amostras de queijo tipo Minas Padrão comercializado no Município de São Luis, Maranhão em 2007.

\begin{tabular}{llll}
\hline & \multicolumn{3}{c}{ Micro-organismos (UFC/g) } \\
\cline { 2 - 4 } Valores & Mesófilos & Psicotróficos & Staphylococcus spp. \\
\hline Mínimo & $<10$ & $8,3 \times 10^{3}$ & $<10$ \\
Médio & $5,4 \times 10^{6}$ & $1,2 \times 10^{7}$ & $1,7 \times 10^{5}$ \\
Máximo & $1 \times 10^{8}$ & $1,2 \times 10^{8}$ & $\geq 8,5 \times 10^{6}$ \\
\hline
\end{tabular}


Tabela 2 - Número de amostras de queijo tipo Minas Padrão, quanto a presença de Staphylococcus coagulase positiva, comercializado no Município de São Luis, Maranhão em 2007.

\begin{tabular}{lc}
\hline UFC/g de Staphylococcus & Amostras \\
\hline$<1,0 \times 10^{2}$ & 0 \\
$1,0 \times 10^{2} \neg 5,0 \times 10^{2}$ & 0 \\
$5,0 \times 10^{2} \neg 5,0 \times 10^{3}$ & 0 \\
$5,0 \times 10^{3} \neg 5,0 \times 10^{4}$ & 0 \\
$>5,0 \times 10^{4}$ & 2 \\
\hline Total & 2
\end{tabular}

Anvisa: $<5,0 \times 10^{2}$

Segundo Jay (1994) apud FerNANDES et al. (2006) o Staphylococcus coagulase positiva multiplica-se em temperaturas compreendidas entre 7,0 e $47,8^{\circ}$ $\mathrm{C}$, com temperatura ótima de $37^{\circ} \mathrm{C}$; suas toxinas são produzidas entre 10 e $46^{\circ} \mathrm{C}$, com temperatura ótima de 40 a $45^{\circ} \mathrm{C}$. A má utilização da temperatura durante o processo de transporte e conservação de alimentos pode contribuir com a multiplicação de micro-organismos patogênicos, como o Staphylococcus coagulase positiva, sendo um importante fator no controle de qualidade de produtos alimentícios.

Quanto à pesquisa de Salmonella spp., não foi detectado em $25 \mathrm{~g}$ de nenhuma das amostras contaminação por este micro-organismo, sendo esse resultado satisfatório por apresentar-se dentro dos padrões estabelecidos pela Anvisa (BRASIL, 2001), que estabelecem ausência desse micro-organismo em $25 \mathrm{~g}$ de alimento. A ausência de Salmonella spp. nas amostras pode estar relacionada à presença de bactérias láticas, que tornam o queijo um meio adverso à sobrevivência de micro-organismos patogênicos ou pela condição estressante advinda do processamento e estocagem a que o alimento é submetido (Sharp, 1981 e Flowers et al., 1992 apud Almeida et al., 2003).

\section{CONCLUSÃO}

Nas condições em que a pesquisa foi realizada e baseando-se no número de amostras analisadas e pelos resultados encontrados, pode-se concluir que o produto analisado apresentava condições higiênico-sanitárias insatisfatórias, e que a contaminação por Staphylococcus coagulase positiva, evidenciada em algumas amostras, pode oferecer risco à saúde dos consumidores. Com isso faz-se necessária uma maior fiscalização por parte dos órgãos competentes tanto na indústria quanto nos pontos de comercialização.

\section{REFERÊNCIAS}

ALMEIDA, P.M.P.; FRANCO, R.M. Avaliação bacteriológica de queijos tipo Minas Frescal com pesquisa de patógenos importantes à saúde pública: Staphylococcus aureus, Salmonella sp. e Coliformes fecais. Higiene Alimentar, v.17, n.111, p.79, 2003.

ARAUJO, W.; SILVA, M.H.; MARTINEZ, T.C.N.; SILVEIRA, V.F.; BARROS, S.L.B.; SILVA, A.A.F. Isolamento e identificação de coliformes no queijo minas comercializado na região metropolitana de Salvador-BA. Revista Brasileira Saúde Produção Animal, v.2, n.2, p.37-42, 2001.

ARRUDA, M.L.T.; NICOLAU, E.S.; REIS, A.P.; ARAÚJO, A.S; MESQUITA, A.J. Ocorrência de Staphylococcus coagulase positiva em queijos Minas ti.pos frescal e padrão comercializados nas feiras-livres de Goiânia-GO. Revista Instituto Adolfo Lutz, v.66, n.3, p.292-298, 2007.

ÁVILA, C.R.; GALLO, C.R. Pesquisa de Salmonella sp. em leite cru, leite pasteurizado tipo C e quijo "Minas Frescal" comercializado no município de Piracicaba-SP. Scientia Agrícola, v.53, n.1, p.159-163, 1996.

BORGES, M.F.; FEITOSA, T.; NASSU, R.T.; MUNIZ, C.R.; AZEVEDO, E.H.F.; FIGUEIREDO, E.A.T. Microrganismos patogênicos e indicadores em queijo de coalho produzido no Estado do Ceará, Brasil. Boletim do Centro de Pesquisa e Processamento de Alimentos, v.21, n.1, p.31-40, 2003.

BRASIL. AGÊNCIA NACIONAL DE VIGILÂNCIA SANITÁRIA. Resolução RDC n.12, de 2 de janeiro de 2001. Aprova o regulamento técnico sobre padrões microbiológicos para alimentos. Disponível em: <http:/ / www. anvisa.gov.br/legis/resol>. Acesso em: 12 dez. de 2006.

BRASIL. Ministério da Agricultura, Pecuária e Abastecimento. Instrução Normativa $n^{\circ} 62$, de 26 de agosto de 2003. Métodos Analíticos Oficiais para Análises Microbiológicas para Controle de Produtos de Origem Animal e Água. 2003.

BRYAN, F.L. Análise de risco nas empresas de alimentos. Higiene Alimentar, v.3, n.2, p.92-100, 1984.

FERNANDES, A.M.; ANDREATTA, E.E; OLIVEIRA, C.A.F. Ocorrência de bactérias patogênicas em queijos no Brasil: questão de saúde pública. Higiene Alimentar, v.20, n.144, p.46-49, 2006.

FLOWERS, R.S.; D'AOUST, J.; ANDREWS, W.H.; BAILEY, J.S. Salmonella. In: VANDERZANT, C.; SPLITTSTOESSER, D.F. (Ed.). Compendium of methods for the microbiological examination of foods. 3.ed. Washington, APHA, 1992. cap. 25, p.371-422.

FRANCO, R.M.; ALMEIDA, L.E.F. Avaliação microbiológica de queijo ralado, tipo parmesão, comercializado em Niterói, RJ. Higiene Alimentar, v.6, n.21, p.33-36,

1992. 
INTERNATIONAL COMITEE ON MICROBIOLOGICAL SPECIFICATION FOR FOOD MICRORGANISMS IN FOOD. ICMSF. I - Their significance and methods of enumeration. 2.ed. Toronto: University Press, 2000. 439p.

JAY, J.M. Microbiologia mderna de los alimentos. 3.d. Zagaroza: Acribia, 1994. 804p.

PEREIRA, L.S. Qualidade microbiológica e físico-química do queijo coalho comercializado na cidade de São Luis-MA. 2006. Monografia (Graduação em Medicina Veterinária) - Setor de Ciências Agrárias, Universidade Estadual do Maranhão, São Luis 2006.

PERESI, J.T.M.; GRACIANO, R.A.S.; ALMEIDA, I.A.Z.C. Queijo Minas tipo Frescal Artesanal e Industrial: qualidade macroscópica, microscópica e teste de sensibilidade aos agentes antimicrobianos. Higiene Alimentar, v.15, n.83, p.63, 2001.

RAIMUNDO, S.M.C. Qualidade microbiológica do queijo Minas frescal no comércio do Rio de Janeiro. Revista do Instituto de Laticínios Cândido Tostes, v.47, p.169-173, 1992.

REIS, J.A.; HOFFMANN, P.; HOFFMANN, F.L. Ocorrência de bactérias aeróbias mesófilas, coliformes totais, fecais e Escherichia coli, em amostras de águas minerais envasadas, comercializadas no município de São José do Rio Preto, SP. Higiene. Alimentar, v.20, p.145, p.109-115, 2006.

PESSOA, G.V.A.; SILVA, C.A.M. Meios de Rugai e lisina-motilidade combinados em um só tubo para identificação presuntiva de enterobactérias. Revista Instituto Adolfo Lutz, v.32, p.97-100, 1972.

BRASIL. Ministério da Agricultura, Pecuária e Abastecimento. Departamento de Inspeção de Produtos de Origem Animal. Decreto 2244 de 04 de junho de 1997: Regulamento da Inspeção Industrial e Sanitária de Produtos de Origem Animal. Brasília, DF: Riispoa, 1997. Título VII, cap. IV, art. 598 e 614.
SALOTTI, B.M.; CARVALHO, A.C.F.B.; AMARAL, L.A.; VIDAL-MARTINS, A.M.C.; CORTEZ, A.L. Qualidade microbiológica do queijo minas frescal comercializado no município de Jaboticabal, SP, Brasil. Arquivos do Instituto Biológico, São Paulo, v.73, n.2, p.171-175, 2006.

SANTOS, F.A.; NOGUEIRA, N.A.P; CUNHA, G.M.A. Aspectos microbiológicos do queijo tipo "coalho" comercializado em Fortaleza-CE. B. CEPPA, v.13, n.1, p.31-36, 1995.

SCHEID FILHO, V.B.; ROOS, T.B.; OLIVEIRA, D.S.; TIMM, C.D. Contagem de bactérias mesófilas e psicrotróficas em queijo colonial. In: CONGRESSO BRASILEIRO DE MICROBIOLOGIA, 22., 2004, Florianópolis. Anais. Florianópolis, 2004.

SILVA JUNIOR, E.A. Contaminação microbiológica como indicadora das condições higiênico-sanitárias de equipamentos e utensílios de cozinhas industriais para a determinação de pontos críticos de controle. 1992. 83f. Dissertação (Mestrado) - Universidade de São Paulo, São Paulo, 1992.

SHARP, M.E. Microbiology of ceese. Dairy Microbiology, v.2, p.1-157, 1981.

SHILLING, M. Qualidade em nutrição. São Paulo: Varela, 1995. p.79-83.

SOUSA, C.L.; TORO, M.U.; NEVES, E.C.A. Avaliação microbiológica e físico-química do queijo cottage comercializado na cidade de Belém-PA. Higiene Alimentar, v.19, n.133, p.86-91, 2005.

VANDERZANT, C.; APLITTS-TOESSER, D.F. Compendium for the microbiological examination of foods. 3.ed. Washington, D.C.: American Public Health Association, 1992. 1219p.

Recebido em 8/7/08

Aceito em 16/5/09 